EFPT Psychotherapy Guidebook • EFPT Psychotherapy Guidebook

\title{
Cognitive Behavioural \\ Therapy for Insomnia (CBT-
}

Hugo Canas-Simião ${ }^{1}$, Helena Kisand ${ }^{2}$

${ }^{1}$ Centro Hospitalar de Lisboa Ocidental, ${ }^{2}$ University of Tartu

Published on: Dec 05, 2020

DOI: $10.21428 /$ fc0b32aa.aeeb8c1d

License: Creative Commons Attribution 4.0 International License (CC-BY 4.0). 


\section{Brief historical overview}

Cognitive Behavioral Therapy for Insomnia (CBT-I) is a specific wing of Cognitive Behavioral Therapy (CBT) - an evidence based form of psychotherapy which integrates various currents of scientific psychology, mainly Behavioral Therapy and Cognitive Therapy ${ }^{(1)}$ - applied for the treatment of chronic insomnia.

Cognitive-behavioral psychotherapy aims to help the patient to change thoughts and behaviors that harm him by encouraging him to adopt changes in his daily life and discussing the results of these changes session by session. For a brief historical overview about general CBT, check the Cognitive Behavioural Therapy chapter.

The Behavioral Model of Insomnia was put forward by Spielman and Colleagues in $1987^{(4)}$ and is the first and most widely cited theory regarding the etiology of chronic insomnia ${ }^{(3)}$. As shown in Figure 1, it conceptualizes acute insomnia with both predisposing and precipitating factors and how it develops to chronic insomnia maintained by maladaptive coping behaviours (perpetuating factors) ${ }^{(3,4)}$.
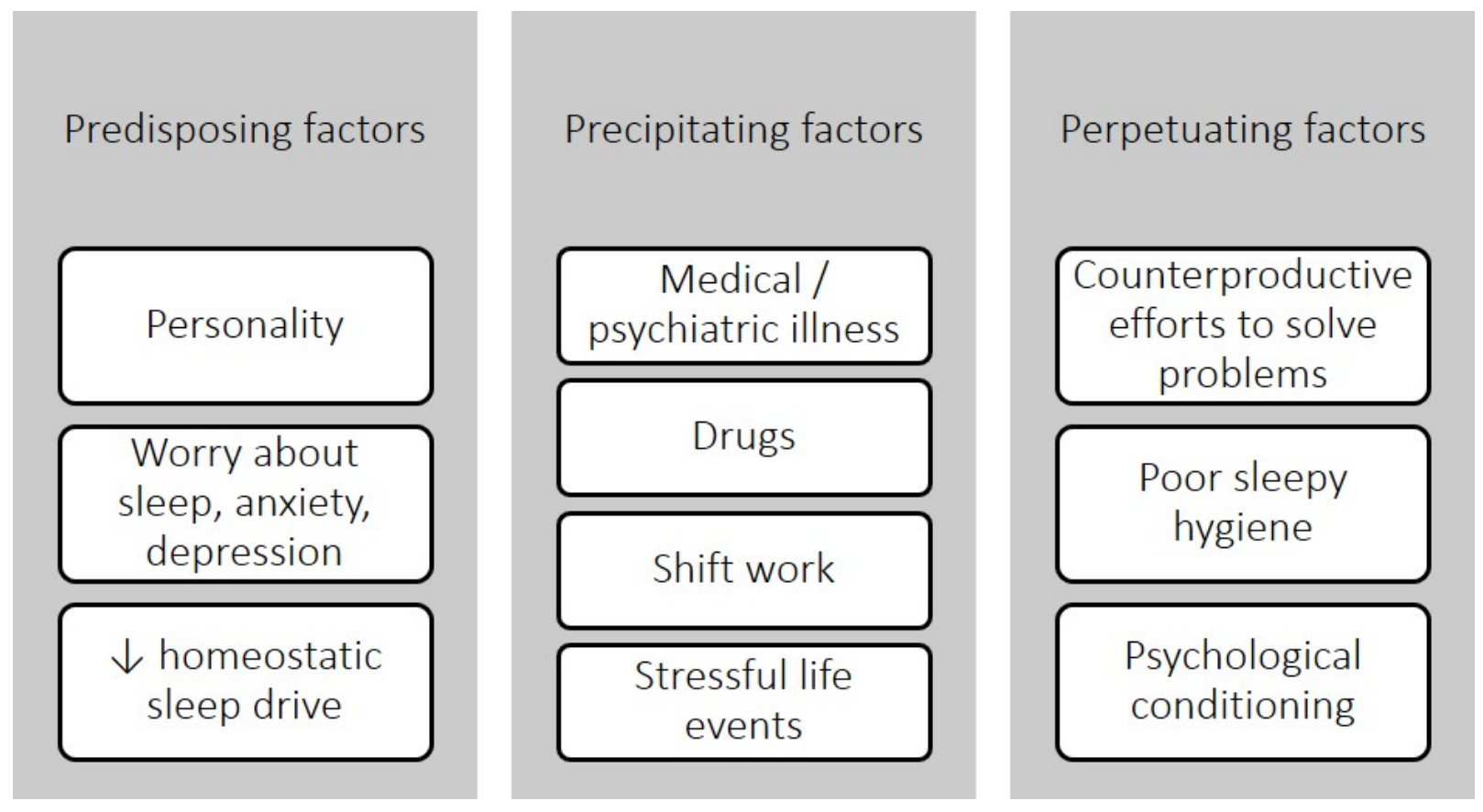

Figure 1. Summary of behavioral model of insomnia.

Validation of cognitive models for anxiety disorders and studies on the cognitive processes of insomnia majorly contributed to the development of cognitive models for insomnia (5). As explained by Harvey (2002), the cognitive model of insomnia (Figure 
2) suggests individuals who suffer from insomnia have an excessive negative cognitive activity (like the importance of getting enough sleep and the impact the sleep disturbance is having on health and/or daytime functioning) which triggers autonomic arousal (as a result of sympathetic nervous system activation) and emotional distress, which triggers selective attention towards any sleep-related threat cues and, thus, fuels the negative cognitive activity and distress ${ }^{(5)}$.

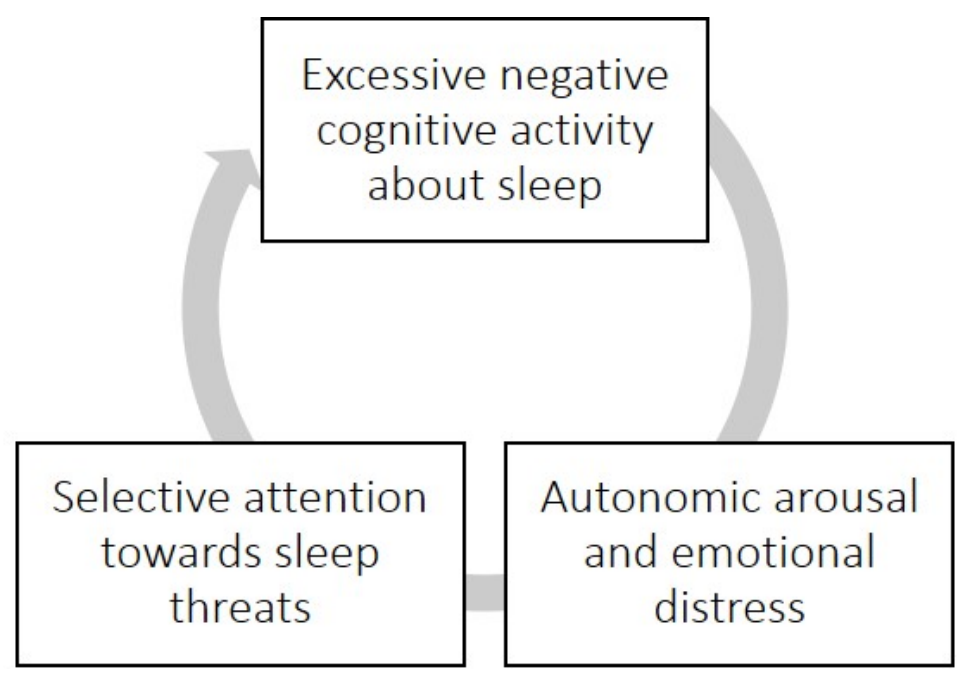

Figure 2. Summary of the cognitive model of insomnia.

While not formally described in the Spielman model, an increase in non-sleep related behaviours in the bedroom is also considered a perpetuating factor, which is thought to produce stimulus dyscontrol ; for instance, not being able to fall asleep while lying in bed if one isn't reading or watching tv ${ }^{(3)}$. This concept is the pillar to Bootzin's Stimulus Control perspective on insomnia, previously described in $1972^{(3,6)}$.

\section{Description}

CBT-I usually consists of :

- psychoeducation: basic information about normal sleep and age-related changes in sleep patterns ${ }^{(7)}$;

- sleep hygiene: practices and environmental factors that may promote or disrupt sleep ${ }^{(7,8)}$;

- relaxation training: clinical procedures aimed at decreasing intrusive thoughts at bedtime (e.g. imagery training, meditation) or somatic tension (e.g. progressive muscle relaxation, autogenic training) ${ }^{(7)}$. 
- stimulus control therapy: a set of behavioural instructions designed to re-associate the bed or bedroom with sleep and to re-establish a consistent sleep-wake schedule $(6,7)$;

- sleep restriction therapy: method designed to curtail the time in bed to the actual amount of sleep being achieved ${ }^{(4,7)}$;

- and cognitive therapy: psychological methods designed to identify, challenge and change misconceptions about sleep and faulty beliefs about insomnia and its perceived daytime consequences $(7,9)$.

It is generally performed in 4-8 sessions and it can be done either in group or individually ${ }^{(7)}$.

\section{Main uses (indications)}

First line treatment for Chronic Insomnia Disorder (7).

Behavioral strategies are the first line of treatment for patients with Alzheimer's Disease and Chronic Insomnia Disorder (7).

\section{Efficacy}

According to the European guideline for the diagnosis and treatment of insomnia, published in $2017^{(7)}$, there are 15 published meta analyses on the efficacy of CBT-I for 'primary' insomnia as well as CBT-I for co-morbid insomnia.

CBT-I has a positive impact on both insomnia complaints and co-morbid symptoms ${ }^{(7)}$.

There is also evidence supporting brief versions of CBT-I (e.g. two face-to-face sessions and two telephone calls) ${ }^{(10)}$ or just one session for acute insomnia ${ }^{(11)}$.

Four meta-analyses on internet-based CBT-I showed good treatment efficacy; however, the efficacy was lower than for face-to-face CBT-I ${ }^{(7)}$.

\section{Quotes from an expert on CBT-I}

"Once insomnia becomes chronic, the only effective treatment is cognitive behavioural therapy. All international authorities and clinical guidelines agree on this. Sleeping pills are not recommended for more than a few nights' use, and do not have an evidence base for long-term use. Although some people make sensible use of these pills (called hypnotics) for extended periods, the very fact they do so illustrates that 
they seldom solve insomnia." - Colin Espie, Professor of Sleep Medicine in the Nuffield Department of Clinical Neuroscience.

\section{Comment from an expert on CBT-I and reviewer of this chapter}

"A brief period of insomnia, caused by precipitating stressful life events may evolve into a case of learned chronic insomnia through a combination of worry about sleep and maladaptive sleep habits. For this reason, treatment of chronic insomnia relies on changing the thoughts and behaviours that play the main role in perpetuating insomnia. CBT-I intervention identifies these "learned" thoughts and behaviours and helps patients "unlearn" them and thus breaking the insomnia cycle." - Maria Serra Brandão, Sleep Psychologist.

\section{Comment from the authors as trainees on CBT-I}

"CBT-I is an easy to learn psychotherapy that is the first line of treatment for chronic insomnia disorder. I've started to learn how to apply CBT-I in a masterclass with Professor Collin Espie (University of Oxford) and during my time as trainee in CENC (a Sleep Medicine Center in Portugal). Since I've started to apply these techniques with my patients, many of them are no longer using benzodiazepines as sleeping aids and their lifestyle got healthier." - Hugo Canas Simião

"During my time as a trainee at a sleep medicine center, I was able to observe and help to deliver CBT-I. It is not easy for patients to make the required changes, but I was amazed to see how deeply sleep quality is intertwined with mental health in general and how quite a short therapy intervention can truly change peoples' lives for the better. Even patients who have been dependent on hypnotics for a very long time can withdraw from them and improve their sleep if they are truly committed and persistent." Helena Kisand

\section{Books, manual, videos, application, published online courses or international association}

Masterclass in CBT-I: https://www.ndcn.ox.ac.uk/study-with-us/online-programme-insleep-medicine/short-courses/masterclass-in-cbt-i

C. M. Morin, C. A. Espie "Insomnia: A Clinical Guide to Assessment and Treatment" 2003

Perlis, Junquist, Smith, Posner "Cognitive Behavioral Treatment of Insomnia: A Sessionby-Session Guide" 
Oxford online course for sleep medicine: https://www.conted.ox.ac.uk/courses/sleepmedicine-the-physiological-basis-of-sleep-online

CBT-I treatment manual for providers:

https://www.med.unc.edu/neurology/files/2018/05/jdedingrCBTManual.pdf

\section{Links to Societies}

European Sleep Research Society - $\underline{\text { htps://esrs.eu/ }}$

Associação Portuguesa do Sono - https://apsono.com/pt/

\section{Name and short presentation of the trainee}

Hugo Canas-Simião, Psychiatry and Mental Health Department, Centro Hospitalar de Lisboa Ocidental, Lisbon, Portugal.

Helena Kisand, University of Tartu, Estonia.

\section{Bibliography}

1. Barata B, Garaparinho R, Ferreira L, Marques M. (2019). Terapia cognitivocomportamental. In João Borges (coord.), Um guia para as psicoterapias em Portugal. Edições parsifal

2. Spielman A, Caruso L, Glovinsky PA. (1987). Behavioral perspective on insomnia treatment. Psychiatr Clin North Am; 10(4):541-553.

3. Perlis ML, Benson-Jungquist C, Smith MT, Posner DA. (2005). Cognitive behavioral treatment of insomnia: A session-by-session guide. Springer New

York. https://doi.org/10.1007/0-387-29180-6

4. Spielman, A ; Glovinsky P. (1991). The varied nature of insomnia. In P.J. Haun (Ed.). Case studies in insomnia (pp. 1-15). New York. Plenum Press.

5. Harvey AG. (2002). A cognitive model of insomnia. Behav Res Ther. Aug;40(8):86993. Review.

6. Bootzin RR. (1972). Stimulus control treatment for Insomnia.Proceedings,80th Annual Convention,APA;395-396

7. Riemann D, Baglioni C, Bassetti C, Bjorvatn B, Dolenc Groselj L, Ellis JG, Espie CA, Garcia-Borreguero D, Gjerstad M, Gonçalves M, Hertenstein E, Jansson-Fröjmark M, Jennum PJ, Leger D, Nissen C, Parrino L, Paunio T, Pevernagie D, Verbraecken J, Weeß HG, Wichniak A, Zavalko I, Arnardottir ES, Deleanu OC, Strazisar B, Zoetmulder M, Spiegelhalder K. (2017). European guideline for the diagnosis and 
treatment of insomnia. J Sleep Res. Dec;26(6):675-700. doi: 10.1111/jsr.12594. Epub 2017 Sep 5. PubMed PMID: 28875581.

8. Hauri PJ. (1991). Case Studies in Insomnia. Plenum Medical Book Company, New York

9. Morin CM and Espie CA. (2004). Insomnia - A Clinical Guide to Assessment and Treatment. Springer, New York.

10. Buysse DJ, Germain A, Moul DE, Franzen PL, Brar LK, Fletcher ME, Begley A, Houck PR, Mazumdar S, Reynolds CF 3rd, Monk TH. (2011). Efficacy of brief behavioral treatment for chronic insomnia in older adults. Arch Intern Med. 2011 May 23;171(10):887-95. doi: 10.1001/archinternmed.2010.535. Epub 2011 Jan 24. Erratum in: JAMA Intern Med. 2019 Jun 17.

11. Ellis, J. G., Cushing, T. and Germain, A. (2015). Treating acute insomnia: a randomized controlledtrialof a "single-shot" ofcognitivebehavioral therapy for insomnia. Sleep, 38: 971-978.

12. Colin Espie "Reset your snooze button: how to beat insomnia” The Guardian. 2019 Feb 8 https://www.theguardian.com/lifeandstyle/2019/feb/08/how-to-beat-insomniasleeplessness-causes-treatment 